\title{
Glassy carbon manufacture using rapid photonic curing
}

\author{
Brent de Boode ${ }^{1,2}$, Chris Phillips ${ }^{1,2}$, Yin Cheung Lau ${ }^{1}$, Arturas Adomkevicius ${ }^{1}$, \\ James McGettrick ${ }^{3}$, and Davide Deganello ${ }^{1,2, *}$ (i) \\ ${ }^{1}$ Welsh Centre for Printing and Coating, Faculty of Science and Engineering, Swansea University, Crymlyn Burrows, \\ Bay Campus, Swansea SA1 8EN, Wales, UK \\ ${ }^{2}$ CAPTURE, Faculty of Science and Engineering, Swansea University, Crymlyn Burrows, Bay Campus, Swansea SA1 8EN, Wales, UK \\ ${ }^{3}$ SPECIFIC, Faculty of Science and Engineering, Swansea University, Crymlyn Burrows, Bay Campus, Swansea SA1 8EN, Wales, UK
}

Received: 17 August 2021

Accepted: 20 October 2021

Published online:

3 January 2022

(C) The Author(s) 2021

\begin{abstract}
Photonic curing was explored as a rapid method for producing glassy carbon coatings, reducing processing time from $\sim 20 \mathrm{~h}$ for conventional thermal processing down to $\sim 1 \mathrm{~min}$. A resole-type thermoset polymer resin coated on steel foil was used as a precursor, placed in a nitrogen purged container and exposed to high energy light ( $\sim 27 \mathrm{~J} / \mathrm{cm}^{2}$ per pulse for up to 20 pulses). Comparison samples were produced at $800{ }^{\circ} \mathrm{C}$ using a conventional nitrogen purged thermal route. For both photonic and conventionally produced coatings, Raman spectroscopy and primary peak XPS data showed $s p^{2}$ bonded carbon, indicative of bulk glassy carbon. This transformation evolved with increasing number of pulses, and therefore amount of energy transferred to the coating. The produced coatings were resilient, highly smooth, with no evidence of surface defects. XPS analysis indicated greater $s p^{3}$ content at the immediate surface $(5-10 \mathrm{~nm})$ for photonic cured carbon compared with thermally cured carbon, likely due to the local environment (temperature, atmosphere) around the surface during conversion. The ability to rapidly manufacture glassy carbon coatings provides new opportunities to expand the window of applications of glassy carbons in coatings towards large-scale high volume applications.
\end{abstract}

\section{Introduction}

Glassy carbon (GC) also known as vitreous carbon, is a non-graphitizing carbon with characteristics intermediate between those of graphite and ceramics
[1, 2]. Non-graphitizing carbons are carbons that consist of graphitic nano-crystallites that are crosslinked between crystals in an isotropic fashion [1]. This structure offers a host of important material properties including substantial hardness, high

Handling Editor: Maude Jimenez.

Address correspondence to E-mail: D.Deganello@swansea.ac.uk 
temperature resistance, impermeability to gases, low electrical resistance, chemical resistance and biocompatibility [1-8]. These properties make it a useful material for electrochemical, corrosion and medical applications among others. GC is commonly used as a reference electrode in electrochemistry [4, 9-14], as corrosion protection for current collectors [6, 15-17] and as a surgical implant material in both humans and animals [7, 8, 18-20].

Glassy carbon is typically produced through the carbonization of a resole-type thermoset resin precursor [21, 22] either as a bulk material or as a film [6, 16, 20, 23-26]. Common precursor resins are phenol formaldehyde and furfuryl alcohol [27]. After coating and prior to heat treatment the precursor is cured by temperature or catalyst [20, 28]. Carbonizing the precursor is achieved by heat treatment in an inert atmosphere with a minimum temperature of $600{ }^{\circ} \mathrm{C}$ although most commercially produced glassy carbon materials are carbonized between 1000 and $2000{ }^{\circ} \mathrm{C}[23,25,26]$. Limitations of this production method are the time and temperature required to carbonize the precursor. Polymer carbonization is a process that generally requires several hours of high temperature thermal treatment, typically in an inert atmosphere, with additional time for ramping the furnace temperature up and down. For a high quality conversion from resin to carbon low ramp rates are used, typically $1-5{ }^{\circ} \mathrm{C} / \mathrm{min}$, this causes the typical conversion time to lie in the order of several hours [24, 29]. The requirement of high temperatures and long carbonization times are bottlenecks in the usability of GC in all its applications. In addition to this, if the material were to be required as a coating then the substrate itself would need to be subjected to the same thermal treatment as the glassy carbon.

Photonic curing is a recently developed alternative technology to the conventional convection methods which currently sees most use in the drying and sintering of printed or coated thin films [30-35]. Photonic curing uses xenon lamps to rapidly pulse high-intensity light, transferring a high energy density to the surface of an object [30]. Photonic curing minimizes the thermal treatment times while allowing conventional oven-comparable temperatures to be reached at the surface of the exposed object [31]. The reduction in time is achieved because there are no requirements for ramping, holding or cooling times as the energy delivery using light is almost instantaneous. An example from Cronon et al. [36] where photonic curing is used to sinter aqueous silver inks shows a reduction in curing time from $90 \mathrm{~min}$ to $9 \mathrm{~ms}$. Photonic curing can also be integrated with roll-to-roll processing [32] and the curing speed allows for a decrease in physical space required in automated, in-line manufacturing as it would replace an otherwise large heat or radiation curing oven [33]. The localised and transient nature of photonic curing also enables the potential use of low-cost, flexible, temperature sensitive components/carrier substrates to be used for thin and thick carbon films that ordinarily could not withstand conventional thermal treatment [33]. Photonic curing pulse parameters, such as lamp power, exposure time and frequency determine the overall power density transferred onto the film [30]. Current applications of photonic curing include the manufacture of flexible printed electronics (such as RFID and photovoltaics) $[31,32]$, where the manufacturing process requires the thermal treatment or chemical conversion/sintering of a film on a temperature sensitive substrate. Photonic curing has been demonstrated to convert a $\mathrm{CuO}$ ink into a $\mathrm{Cu}$ thick-film rapidly on a cheap PET substrate, a process which otherwise requires long thermal treatment times in an inert atmosphere [34]. In this case, no inert atmosphere is required as the energy delivery is faster than rate of copper oxidation. Another application is sintering silver-based inks to improve the conductivity [31] or to improve the electronic properties of $\mathrm{ZnO}$ nano-wires [35]. This method is most suited to surface treatment and is therefore applied to coatings on a carrier material rather than bulk materials.

In this paper, photonic curing is explored as a faster means of converting films of phenol formaldehyde resin into glassy carbon. This paper proposes a novel manufacturing process for glassy carbon using a rapid photonic curing method, which has the ability to cure the coating without adversely affecting the temperature of the substrate while decreasing the conversion time from hours to seconds. The converted resin is then compared against a thermally derived glassy carbon. According to the most recently accepted models [3] the structure of GC consists of predominantly $s p^{2}$ bonded carbon domains that are disordered graphitic sheets, giving it a comparable structure to fullerene. The randomly orientated graphitic sheets give GC its isotropic nature (3). Raman spectroscopy and X-ray photoelectron spectroscopy are therefore used to elucidate the 
structure to focus on bulk (microns) and surface (nanometres), respectively, given their different penetration depths [37, 38], while morphology is compared using a scanning electron microscope and white light interferometry.

\section{Methodology}

\section{Materials}

The selected precursor for glassy carbon is phenol formaldehyde resin, a resole-type thermoset polymer resin [Curaphen 40-852 B60, Bitrez Limited (UK)]. The selected substrate for the precursor deposition is 316 stainless steel foil of 25 micron thickness [Advent Research Materials (UK)].

\section{Conversion to carbon methods}

The resin was coated onto the steel foil substrate using bar coating (PrintCoat Instruments K Control Coater). Close-wound bars sizes " 0 " and "2" (0.05 and $0.15 \mathrm{~mm}$ wire diameters, respectively) were used yielding a theoretical wet coating thicknesses of 4 and 12 microns, respectively, at a speed of cia. $1.1 \mathrm{~m} / \mathrm{min}$. Two different coating thicknesses were used as a result of preliminary tests which revealed the structural integrity limitations of the phenol formaldehyde coatings during the heat treatment stages. The thicker coating (12 micron wet) is used in the conventional thermal conversion because that method experienced delamination with thinner coatings, while thin coatings (4 micron wet) are used for the photonic curing method which experiences delamination for thicker coatings. These limitations are specific to the materials and methodology used in this paper. Ambient temperature and humidity during coating were $22{ }^{\circ} \mathrm{C}$ and $33 \%$, respectively. To permanently crosslink the thermoset resin the manufacturer's suggested conditions were used, a temperature cure of $220^{\circ} \mathrm{C}$ for $30 \mathrm{~min}$ in a convection oven (Votsch VTL 60/90). Carbonization of the cured phenolic resin was then achieved using two different methods: a conventional thermal curing method and the photonic curing method.

The conventional method of producing glassy carbon is heat treatment of the cross-linked phenol formaldehyde precursor in an inert atmosphere. For this work, the coated phenol formaldehyde resin samples were exposed to a set point temperature of $800{ }^{\circ} \mathrm{C}$ which was reached at a ramp rate of $2{ }^{\circ} \mathrm{C}$ per minute in a tube furnace (Carbolite GERO GHA 12/450) with a holding time of $2 \mathrm{~h}$. An inert atmosphere in the furnace was achieved with a constant 1 $\mathrm{L} /$ minute flow of nitrogen gas. This tube furnace required temperatures of $<50{ }^{\circ} \mathrm{C}$ in order to be opened, hence resulting in long average cooling times of $\sim 12 \mathrm{~h}$. These parameters follow conventional processes as established in the literature [23-26, 29, 39]. A maximum carbonization temperature of $800{ }^{\circ} \mathrm{C}$ was selected to prevent excessive softening of the steel carrier substrate.

For the photonic curing method, the coated phenol formaldehyde resin samples were heat treated using a photonic curing system (Novacentrix PulseForge 1200, Austin TX). The selected pulse parameters for carbonization were developed via preliminary testing and were a lamp voltage of $450 \mathrm{~V}$ and a pulse duration of $20000 \mu$ s giving an energy output of $\sim 27 \mathrm{~J} / \mathrm{cm}^{2}$ per pulse. Multiple sequential pulses were performed, up to a maximum of 20 pulses $(5,10$, 15,20 pulses), at a frequency of $0.3 \mathrm{~Hz}$. The sample resided in a dedicated sample holder with a transparent glass window as seen in Fig. 1. The sample holder was continually vented with nitrogen gas to achieve an inert atmosphere and remove the evolving off-gases during treatment. The steps required for both treatments are demonstrated graphically in Fig. 2. The total heat treatment cycle of the conventional method takes $>20 \mathrm{~h}$, whereas the photonic curing method requires up to $64 \mathrm{~s}$ (depending on the number of pulses).

\section{Analysis of carbonized samples}

To characterize the glassy carbon material, Raman spectroscopy, X-ray photoelectron spectroscopy (XPS) and scanning electron microscopy techniques were used. Raman spectra of the carbon coatings were compared using a Renishaw in Via Raman system (Renishaw plc., Wotton-Under-Edge, UK) in backscattering configuration with a $50 \times$ objective lens (NA: 0.50 , spot size $\approx 1 \mu \mathrm{m}$ ) The spectrometer used a laser of $532 \mathrm{~nm}$ excitation wavelength with a maximum power output of $32 \mathrm{~mW}$. The spectrum acquisition parameters were set to $5 \%$ laser power $(=1.6 \mathrm{~mW}), 10 \mathrm{~s}$ exposure time and a grating of 1800 lines $/ \mathrm{mm}$. Raman spectroscopy of this particular wavelength penetrates approximately 0.7-1.0 
Figure 1 Converted carbon coating $(\sim 3 \times 3 \mathrm{~cm}$ surface area) placed in the photonic curing sample holder attached to the nitrogen gas supply.

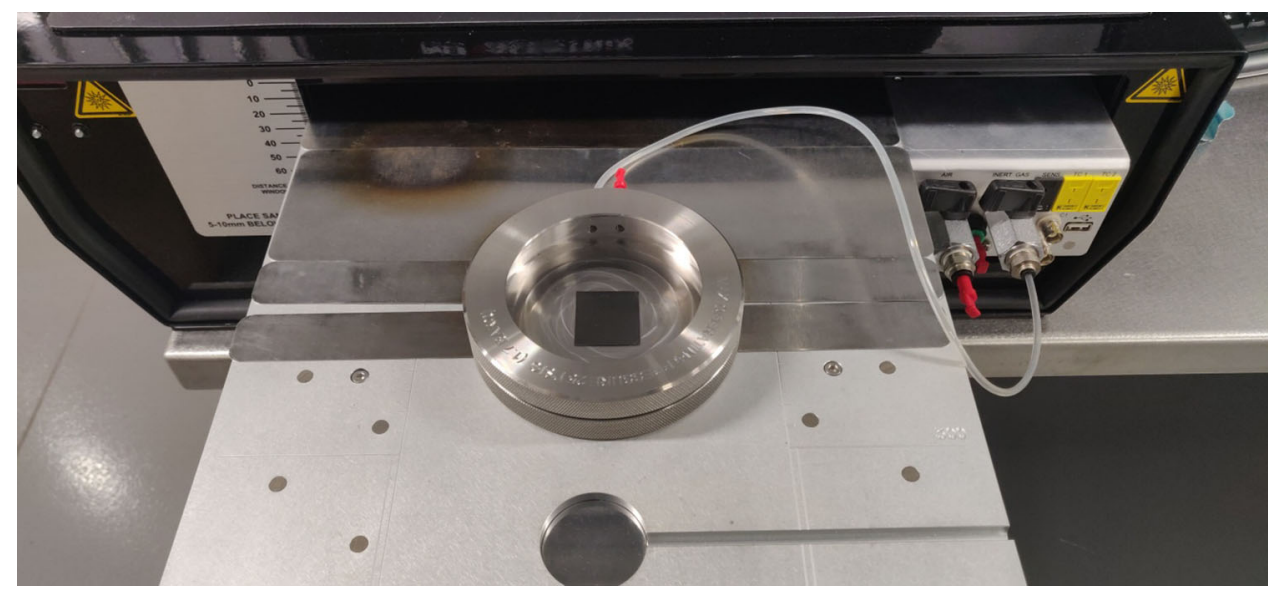

Glass-like Carbon Conversion Methods: Time Scale Comparison

Figure 2 Breakdown of the time requirements of the iterative steps to complete both heat treatment methods.

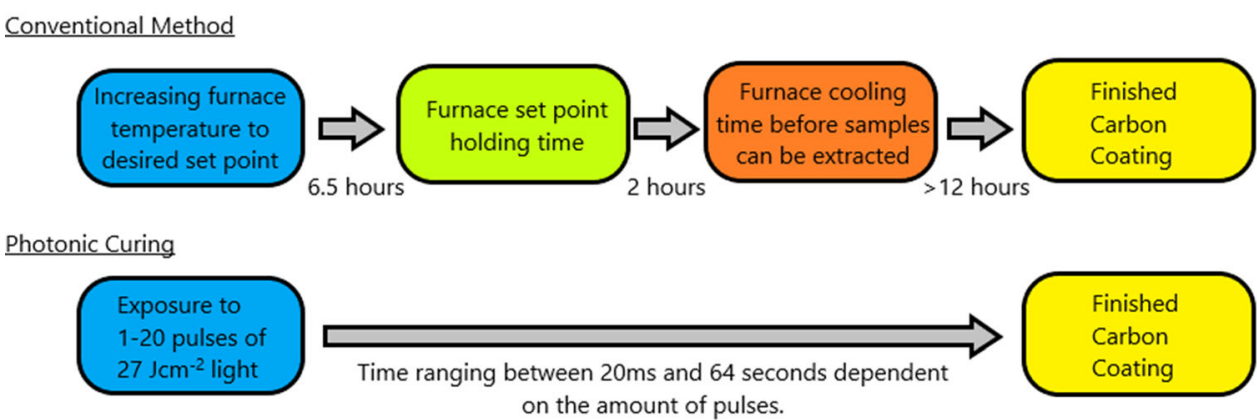

microns in carbon materials which aligns with the typical coating thicknesses used in this study, and therefore is representative of the bulk morphology of the coating $[37,38]$.

X-Ray photoelectron spectra (XPS) were obtained using a Kratos Axis Supra (Kratos Analytical, Manchester, UK) using a monochromated $\mathrm{Al} \mathrm{K \alpha}$ source ( $225 \mathrm{~W}$ power). All spectra were recorded without using a charge neutraliser. Survey scans were recorded at a pass energy of $160 \mathrm{eV}$ and the high resolution data at $40 \mathrm{eV}$ with energy steps of $0.1 \mathrm{eV}$. The emission current was set at $15 \mathrm{~mA}$. Peaks were identified and quantified with Shirley backgrounds and GL(50) line shapes, with carbon D parameter analysis performed as outlined by Kaciulis [40] using CasaXPS Version 2.3.22PR1.0. The photon penetration depth of XPS lies in the range of 5-10 nm $[37,38]$, so that XPS is primarily a surface characterisation method rather than being representative of the bulk.

Scanning electron microscopy [JEOL 7800F with Oxford Instruments Aztec EDS system XMaxN detector field emission gun scanning electron microscope (FEGSEM)] was used to determine the surface topography of the carbon coatings. White light interferometry (NT2000, Veeco Instruments, Inc., Plainview, NY, USA) was used to measure a full three-dimensional surface profile over the coated surfaces in order to evaluate surface roughness. Twenty times magnification was used, giving a measurement area of $232 \mu \mathrm{m}$ by $310 \mu \mathrm{m}$ (at a resolution of $640 \times 480$ pixels with sampling at $485 \mathrm{~nm}$ intervals).

\section{Results and discussion}

\section{Coating topography}

The photonic and thermal cured carbon coatings were both well adhered to the stainless steel substrate under manual handling. Both methods yielded uniform, smooth and durable carbon coatings. The coatings did not readily delaminate when exposed to bending of the coated foil, see Fig. 3 .

SEM images of the photonic cured carbon and thermal cured carbon samples are presented in Fig. 4. To provide a contrast for SEM imaging, between the 
coating and the underlying steel substrate, part of the coating was removed. The images show the photonic cured samples after different exposure times (10, 15 and 20 pulses) as well as the thermal cured material at a magnification of 30000 times. Regardless of the preparation method, the carbon coatings presented a highly smooth surface and were consistent without evidence of any defects such as pinholes, delamination or scratches. Thermal and photonic derived surfaces presented similar visually glossy appearances, showing no discernible difference between the two carbonisation methods.

White light interferometry measurements show a full three-dimensional surface profile over the coated surfaces. A total of 5 measurements are taken for each sample with average surface roughness measurements $(\mathrm{Sa})$ calculated over the measured surface, the errors are calculated using standard deviation. These average surface roughness measurements are compared in Fig. 5. The untreated phenol formaldehyde resin precursor had an average surface roughness, $S a$, of $470 \mathrm{~nm}$. Upon treatment, the roughness of the surface was reduced, and the $S a$ values of both the photonic cured carbon coatings and the thermal cured carbon coating were similar and in the range of 110-140 nm. This data demonstrate that both thermal and photonic carbonization methods resulted in similar carbon surface topographies.

\section{Raman spectroscopy of treated materials}

Raman spectroscopy of carbons revolves around 4 major peaks; $D, D^{\prime}, G$ and $T$ band peaks (at around
1360, 1620, 1590 and $1060 \mathrm{~cm}^{-1}$, respectively). From the locations, shapes and relative intensities of these 4 peaks the carbon-carbon bond structure can be deduced. The two main $s p^{2}$ bonded carbon peaks are the $D$ band (carbon ring breathing mode) and the $G$ band ( $s p^{2}$ bonded carbon stretching mode) at $\sim 1360 \mathrm{~cm}^{-1}$ and $\sim 1590 \mathrm{~cm}^{-1}$, respectively. The $T$ peak $\left(\sim 1060 \mathrm{~cm}^{-1}\right)$ is an indicator for $s p^{3}$ bonded carbon in the sample. The $D^{\prime}$ peak is an indicator of the grain size of the carbon material, located at $1620 \mathrm{~cm}^{-1}$ [41-44]. This $D^{\prime}$ peak becomes more prominent as the grain size increases, which in the case of glassy carbons is associated with an increase in carbonization temperature. From the amorphization trajectory in the study of disordered carbons by Ferrari et al. [45], the $G$ band location and the relative intensity ratio between the $D$ and $G$ band [referred to as $I(D / G)$ ] can be used to estimate the relative $s p^{2}$ and $s p^{3}$ content of the carbon samples.

The Raman spectra of photonic cured (5, 10, 15 and 20 pulses) and thermal treated coatings are compared in Fig. 6. Mean $I(D / G)$ ratios are indicated together with standard deviation based on three repeat measurements at different locations on each sample. The Raman spectra of the polymer precursor without thermal treatment were not Raman active. The Raman spectrum of the conventionally thermal treated coatings showed the typical glassy carbon shape that would be produced at the low end of the typical heat treatment temperature (HTT) range. The $D$ peak was less intense than the $G$ peak, whereas its fullwidth half maximum (FWHM) was approximately 3 times that of the $G$ peak. The secondary peaks in the
Figure 3 Carbon coating on stainless steel substrate flexed in multiple directions to test adhesion.
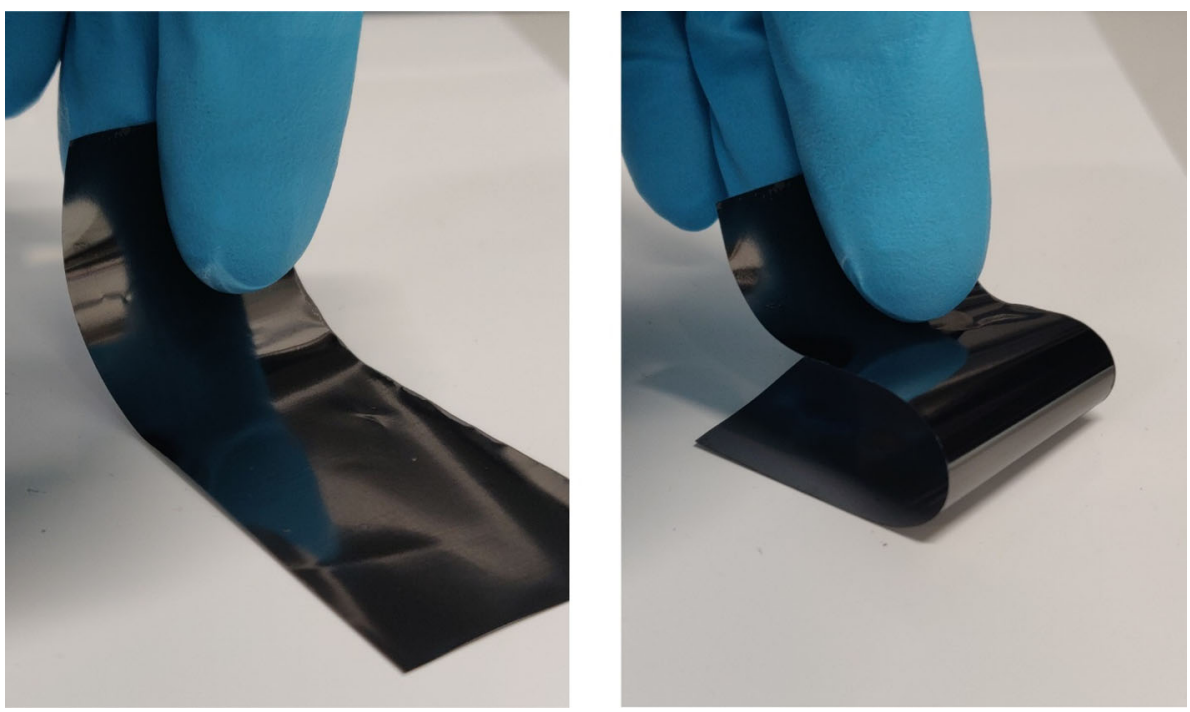
Figure 4 Scanning electron microscopy images of photonic cured carbon coatings at different amounts of pulses and thermal cured carbon with exposed stainless steel substrate at 30000 magnification. A 10 pulses, B 15 pulses, C 20 pulses, D thermal cured carbon.
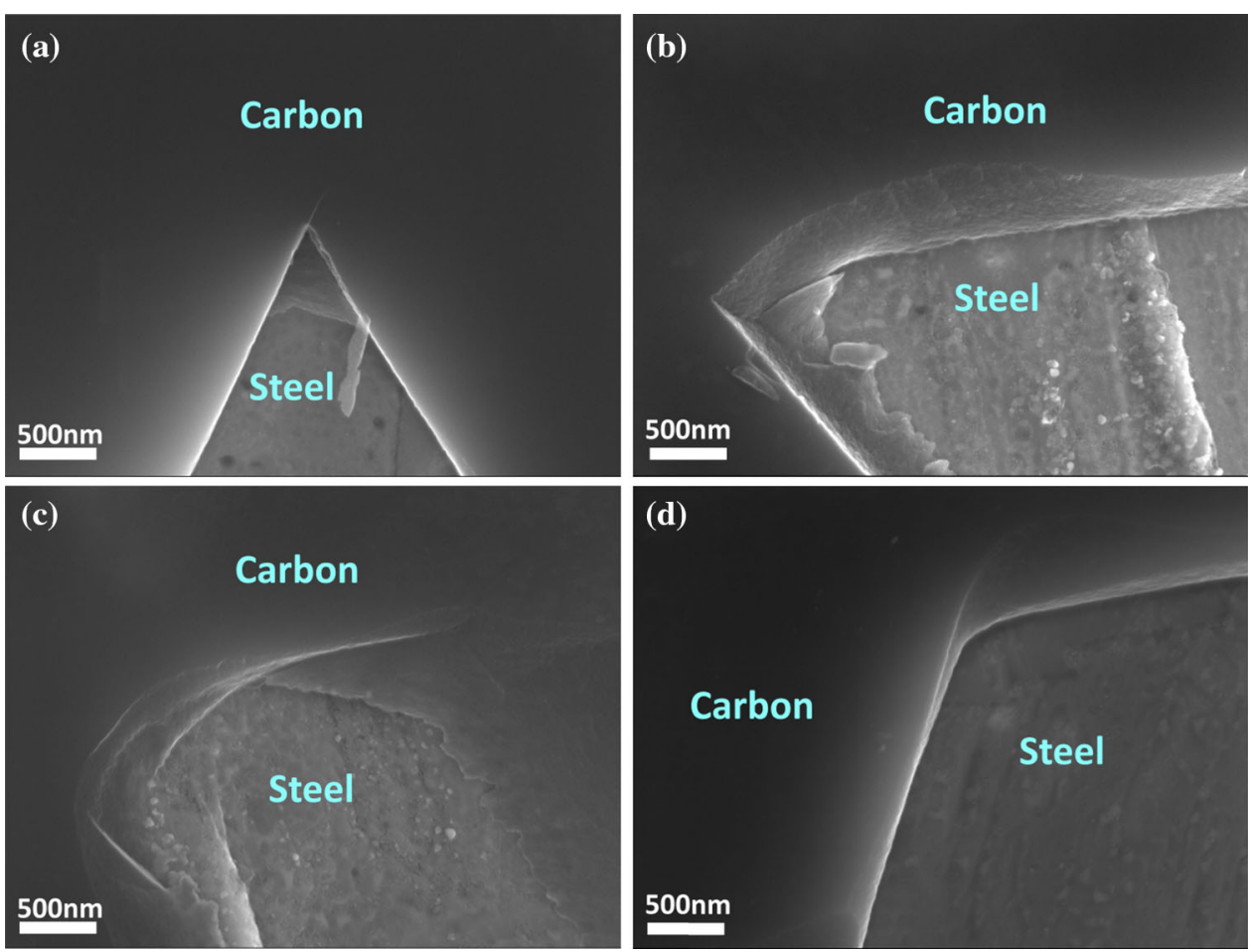
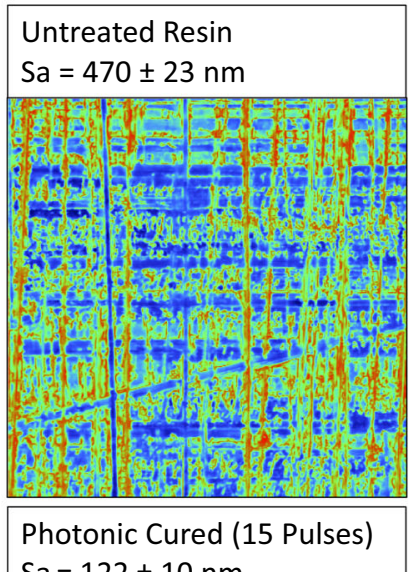

$\mathrm{Sa}=122 \pm 10 \mathrm{~nm}$

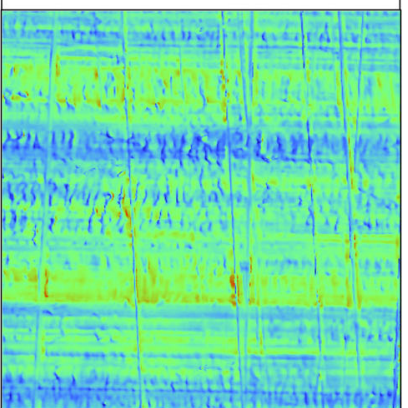

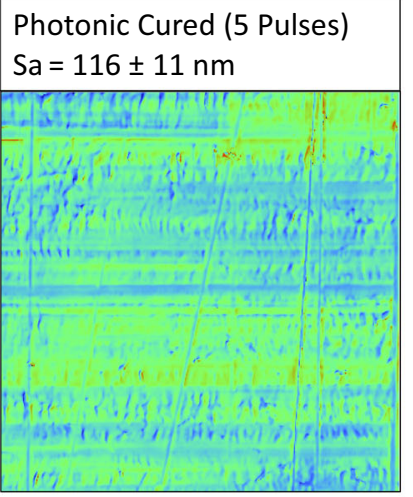

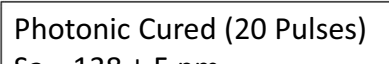

$\mathrm{Sa}=138 \pm 5 \mathrm{~nm}$

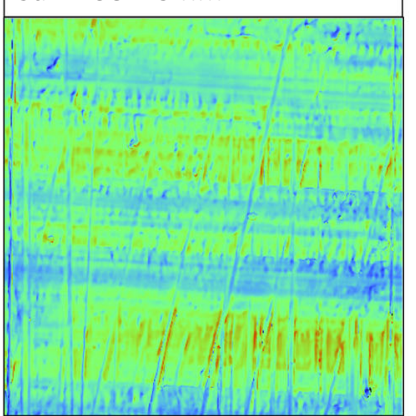

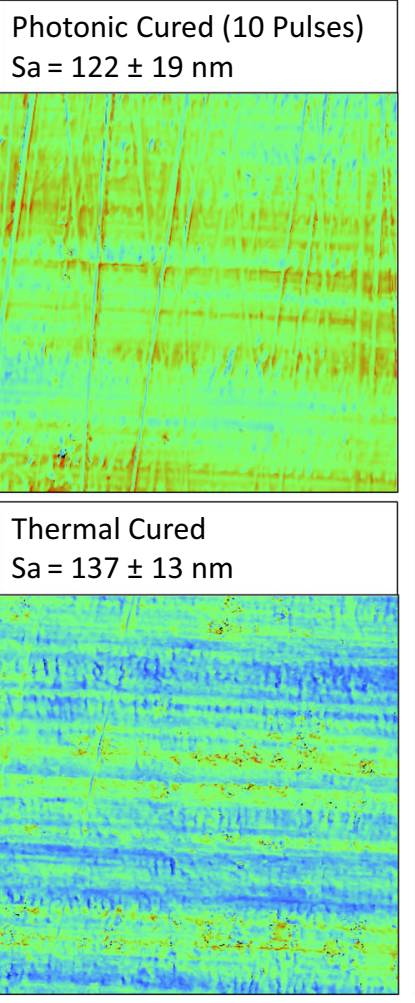

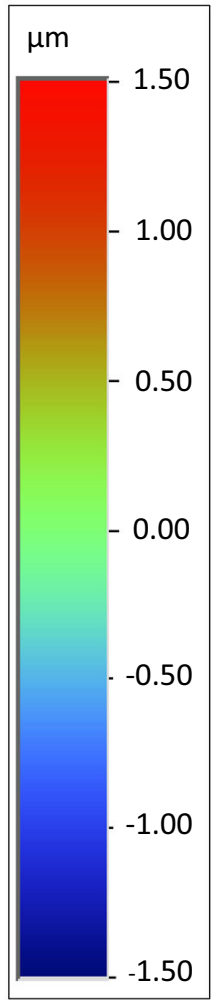

Figure 5 White light interferometry images of phenol formaldehyde resin, photonic cured carbon samples and thermal cured glassy carbon. All Images are of $200 \times 200 \mu \mathrm{m}$ dimensions. 


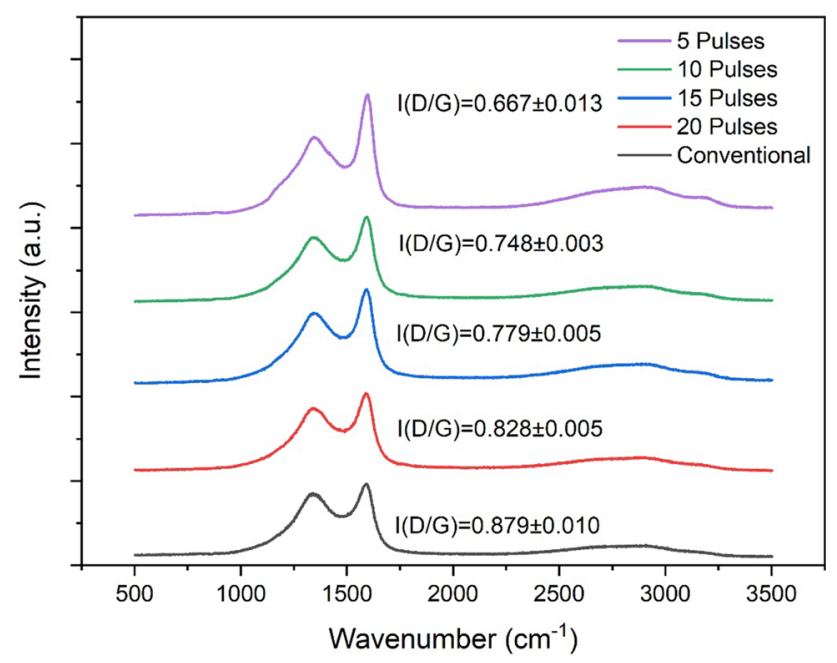

Figure 6 Raman spectra of photonic curing progression compared to conventional carbonization method.

2000-3500 $\mathrm{cm}^{-1}$ range were present but at low intensity and merged. All these Raman characteristics are typical of low HTT glassy carbon from the literature [38, 39, 42, 43, 46, 47].

For the photonic cured samples, progressing through the number of pulses emitted, the first Raman active sample was observed after 5 consecutive pulses, amounting to a total of $100 \mathrm{~ms}$ exposure time and $\sim 135 \mathrm{~J} \mathrm{~cm}^{-2}$ energy density exposure. A bulge was evident at $\sim 1150 \mathrm{~cm}^{-1}$ in the sample subjected to 5 pulses, but it steadily diminished with longer photonic curing treatment (Fig. 6). Carbon $D$ and $G$ band peaks were present in all samples, the $D^{\prime}$ peak was obscured by the $G$ band peak suggesting a small grain size in the carbon coatings which is consistent with the relatively low carbonization temperatures used to produce these coatings $[45,46]$. There was an increase in the intensity ratio between the $D$ and $G$ band as the number of pulses increased, starting with an $I(D / G)$ ratio of 0.67 after 5 pulses, increasing to 0.83 after 20 pulses, and compared to 0.88 for conventional thermal treatment. A high degree of consistency was observed in repeat measurements on the same sample, with standard deviations all being below $2 \%$ of the mean. This increase in $I(D / G)$ with an increase in number of pulses is analogous to behaviour observed in the literature with increases in the heat treatment temperature when producing glassy carbon [39] since more pulses means higher material temperature. From the 'Three stage model' presented by Ferrari et al. [45, 46], it is known that that the combination of a $G$ peak location between 1580 and $1600 \mathrm{~cm}^{-1}$ coinciding with an $I(D /$ $G)$ value ranging between 0.5 and 2.0 indicates a dominance of $s p^{2}$ bonded carbon [38, 39, 42, 43, 46, 47]. Hence, the Raman spectroscopy data show that carbon coatings produced using thermal heat treatment and photonic curing methods both predominantly consisted of $s p^{2}$ bonded carbon.

The 20 pulses photonic cured sample was the most similar to the thermal cured carbon coating. The underlying individual Raman peaks were fitted and compared in more detail for the thermal cured and 20 pulses photonic cured samples in Fig. 7. Both of these spectra consisted of the same primary and secondary peaks, thus demonstrating fundamental similarities between the two resultant carbon coatings. The primary peaks were due to the $D$ band (carbon ring breathing mode) and $G$ band $\left(s p^{2}\right.$ bonded carbon stretching mode) at $\sim 1360 \mathrm{~cm}^{-1}$ and $\sim 1590 \mathrm{~cm}^{-1}$, respectively. The secondary peaks consisted of the $2 D$ band $\left(\sim 2600 \mathrm{~cm}^{-1}\right)$ and the $D+D^{\prime}$ band $\left(\sim 2900 \mathrm{~cm}^{-1}\right)$.

The $G$ band in both carbonization methods is located at $1590 \mathrm{~cm}^{-1}$, the $\mathrm{D}$ bands are in similar positions, $1357 \mathrm{~cm}^{-1}$ for the thermal curing method and $1360 \mathrm{~cm}^{-1}$ for the photonic curing method. The full-width half maximum (FWHM) of the G band peak correlates directly to the measure of disorder, with an increase in FWHM demonstrating greater disorder [45]. The conventional method Raman spectrum $G$ band had a FWHM of $102 \mathrm{~cm}^{-1}$ while the photonic curing $G$ band gave a FWHM of $97 \mathrm{~cm}^{-1}$. This indicates that the materials produced from both methods had similar levels of disorder in their structures.

\section{XPS analysis of treated materials}

The XPS spectra of photonic cured (5, 10, 15 and $20 \mathrm{~s})$ and thermal treated coatings are compared in Fig. 8 and show primary peaks at $\sim 284-285 \mathrm{eV}$ and $\sim$ $531-533 \mathrm{eV}$ binding energies. These two peaks are indicative of carbon-carbon (C1s) and carbon-oxygen (O1s) bonds which are expected for carbon material derived from an organic polymer precursor $[40,48,49]$. Figure 8, further, demonstrates the similarity of the chemical content distribution of the carbon coatings and allows the chemical distribution of each coating to be calculated using the relative areas under the peaks. Conventional method GC coatings contain $\sim 97 \%$ carbon content and $\sim 3 \%$ oxygen 

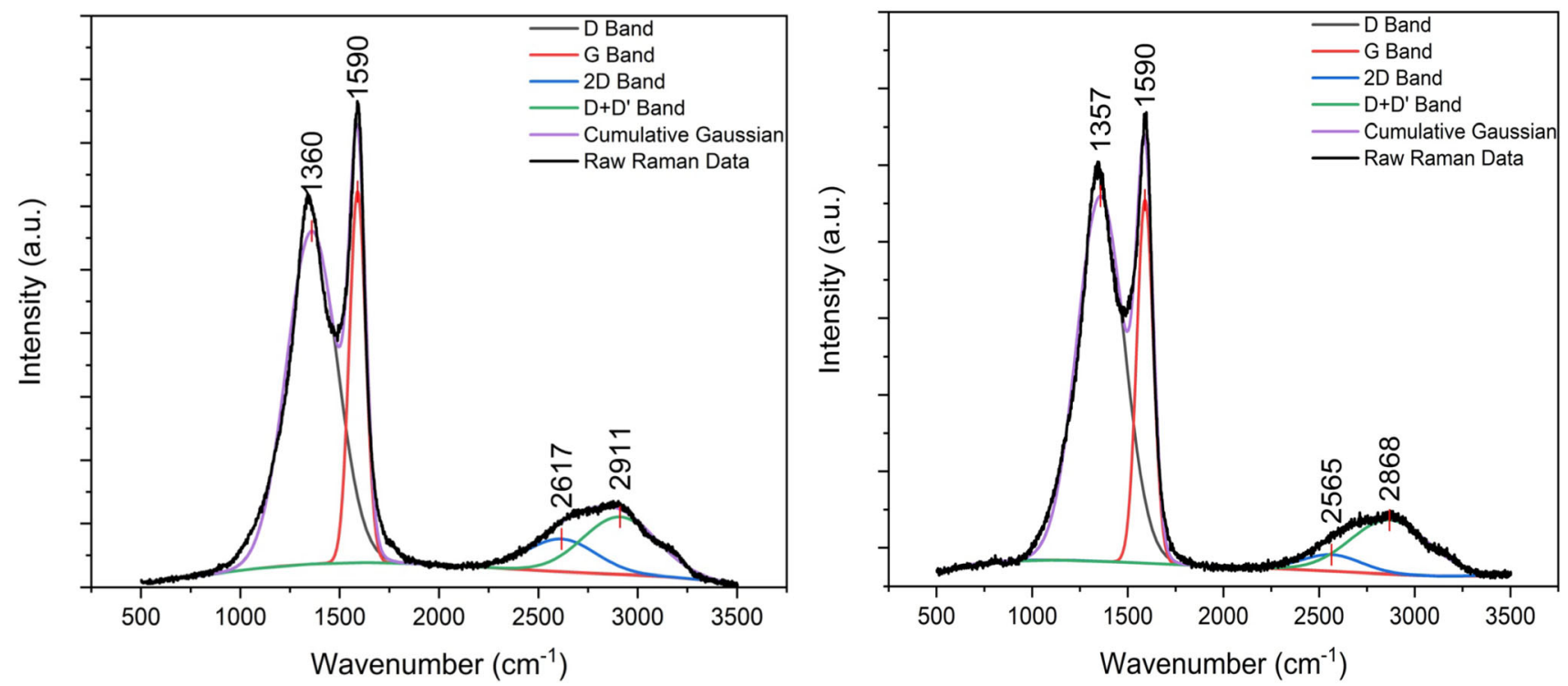

Figure 7 Raman spectroscopy curve fitting of carbon coatings carbonized using the 20 pulses photonic curing method (left) and the thermal curing method (right).

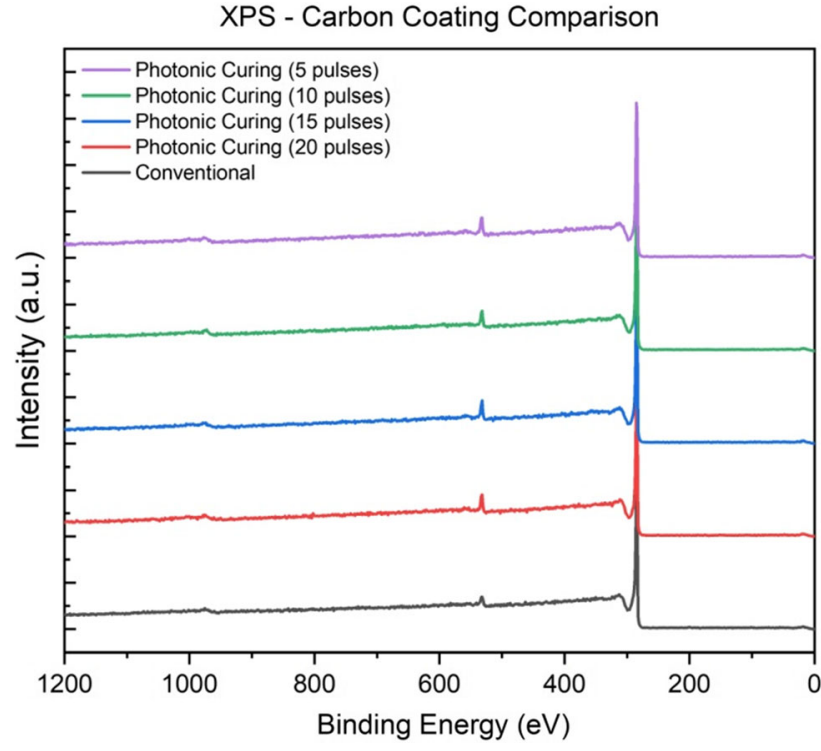

Figure 8 Surface chemistry analysis XPS spectrum comparing carbon coatings manufactured using the photonic curing method (red, blue, green, purple) and the conventional method (black).

content, compared to the photonic cured coatings which contain $\sim 96 \%$ carbon content and $\sim 4 \%$ oxygen content. These values are in line with similar studies on commercially manufactured glassy carbon from Lim et al. (48) and Yi et al. (17).

The primary carbon peaks $(\mathrm{C} 1 \mathrm{~s})$ of the carbon coatings are compared in Fig. 9 against graphite (exclusively $s p^{2}$ bonded carbon) and diamond (exclusively $s p^{3}$ bonded carbon), the reference materials

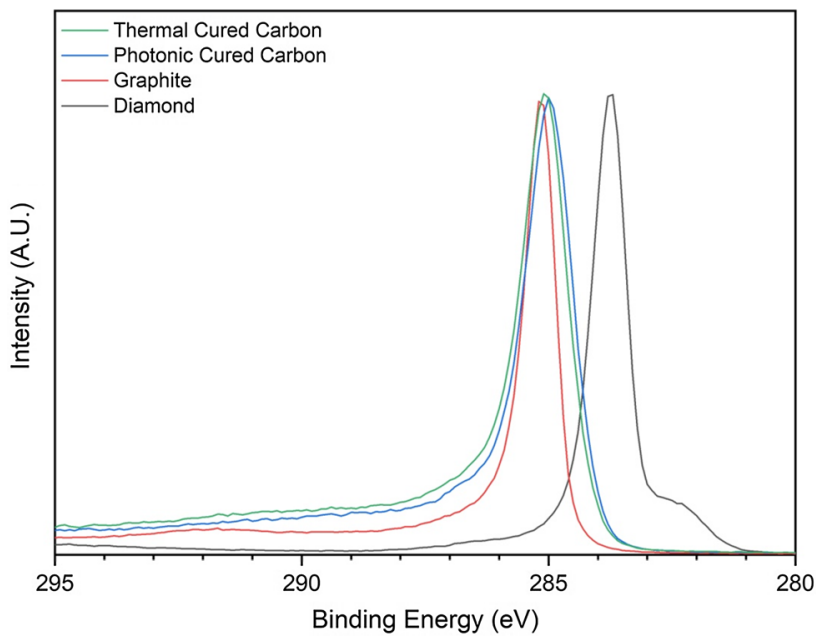

Figure 9 XPS highlighting the carbon $(\mathrm{C} 1 \mathrm{~s})$ peaks exclusively, comparing photonic and thermal cured carbon to reference materials (graphite and diamond).

that reside on either extreme of the carbon bonding spectrum. The location and shape of the peaks in Fig. 9 show that the thermal and photonic cured carbon peaks are located in the same position as the reference graphite sample ( $s p^{2}$ only) at $\sim 285.0 \mathrm{eV}$ and that they are of similar shape, with a high binding energy tail indicative of the presence of $s p^{2}$ carbon. The $s p^{3}$ diamond peak is clearly located at a lower binding energy of $\sim 283.5 \mathrm{eV}$ and has a different shape with a bulge on the lower binding energy side of the peak. Unlike graphite or the glassy 
carbon coatings, with their expected high $\mathrm{sp}^{2}$ carbon content, and ability to resupply electrons, the diamond required charge neutralisation, and hence shifted to a lower binding energy. These results indicate that the photonic cured and thermal cured carbon have similar carbon-carbon bond structures to the graphite reference sample.

A further XPS test was performed on the samples at a higher binding energy (1190-1250 eV) (Fig. 10). In this range, carbon materials have another peak known as the Auger peak (C KLL). This Auger peak is the observation of an electron going through a unique transition between energy levels known as the Auger electron [49, 50]. With mathematical manipulations to the Auger peak data an empirically derived value known as the $D$ parameter can be calculated. The $D$ parameter is defined as the binding energy difference between the position of highest peak and the lowest trough of the Auger peak (C KLL) and is calculated from the first derivative between these positions, and has been used to empirically determine the $s p^{2} / s p^{3}$ bonded carbon ratio of carbon materials [48, 49]. Using the CasaXPS software, the C KLL peak data were smoothed and differentiated as suggested by Kaciulis et al. [40]. Adopting the assumption that diamond has $0 \% s p^{2} /$ $100 \% s p^{3}$ carbon bonds and graphite has $100 \% s p^{2} / 0 \%$ $s p^{3}$ carbon bonds, a linear relationship between the $D$ parameter and the $s p^{2}$ content percentage can be established as demonstrated in Fig. 10 (right). Using this empirical linear relationship, estimates for carbon materials with unknown $\mathrm{sp}^{2} / \mathrm{sp}^{3}$ ratios can be made, leading to thermal cured glassy carbon having an estimated $s p^{2}$ content of $96-100 \%$, while photonic cured carbon on the other hand showed a more even $s p^{2} / s p^{3}$ split at $55 \pm 4 \% s p^{2}$.

The apparent $s p^{2}$ content differed depending on the analysis technique used. Using Raman spectroscopy, predominantly $s p^{2}$ content was observed both for photonic and thermally derived carbon coatings. However, XPS analysis indicated a mixed $\sim 55 \% s p^{2}$ structure for the photonic derived carbon and a much more exclusively $s p^{2}$ structure for the thermally derived carbon coatings. A key distinction between these two analysis techniques is the penetration depth. Raman spectroscopy has a penetration depth of approximately 1 micron for this type of material and is therefore representative of the bulk characteristics of the coating. On the other hand, XPS is focussed on morphology at approximately 5-10 nm from the surface, and is therefore primarily indicative of the surface. This suggests a difference in the morphology at the immediate surface of the photonically cured coating when compared to the bulk. This might be associated with the local environment around the transitioning samples. Conventional thermal conversion takes place in a consistent environment at $800{ }^{\circ} \mathrm{C}$, with a slow and continuously purged carbonisation process. The photonic conversion occurred at close to ambient temperature, with heat directed at the sample surface and not the gas space around it. There are also differences in the rate
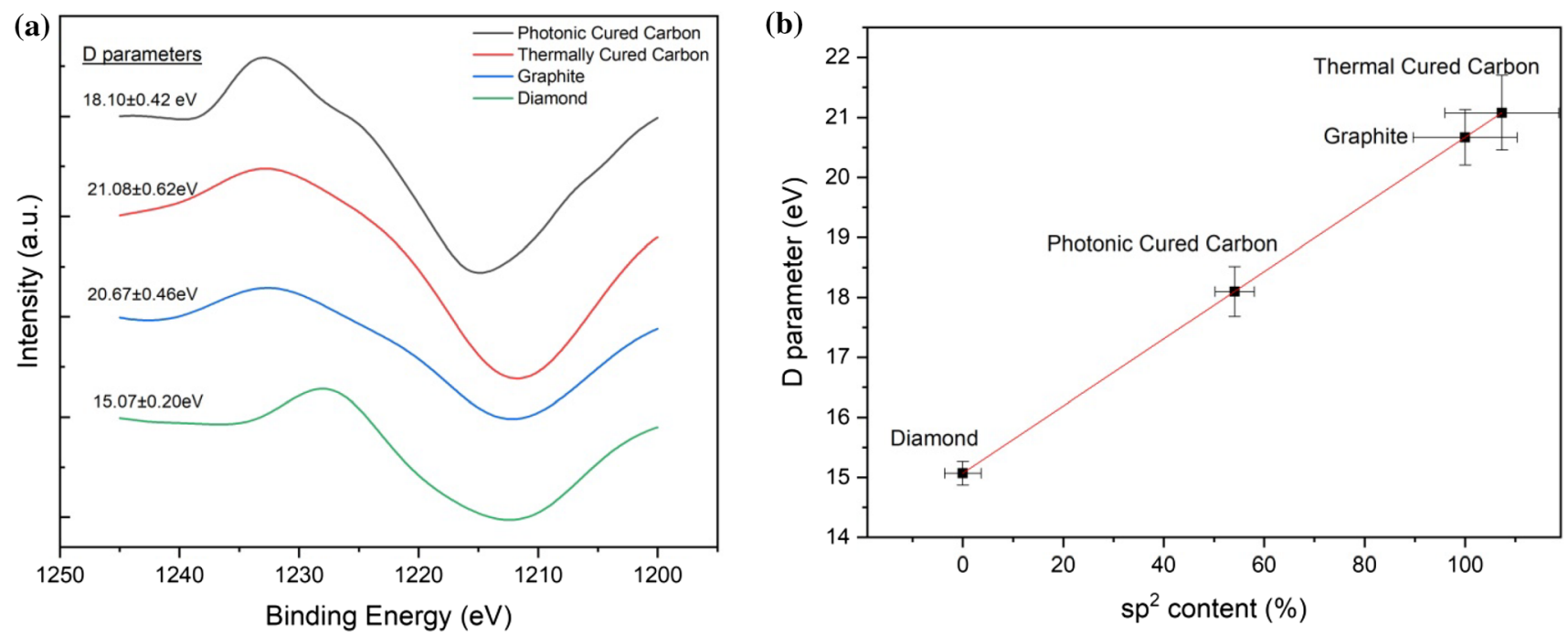

Figure 10 First derivative of Auger peaks of carbons in the 1190-1250 eV range (left) with comparison of the D parameters for evaluation of percentage $s p^{2}$ bonded carbon (right). 
at which the off-gases are produced by the different techniques, which might affect the chemical content of the gas space. This could potentially be explored with a larger sample enclosure and more aggressive purging. Despite this the photonic route offers a rapid means of producing glassy carbon, in seconds or minutes compared to hours, with potential for a host of new applications, even on temperature sensitive substrates which would be destroyed with conventional processing.

\section{Conclusions}

In this study, photonic curing was explored as a method to rapidly produce glassy carbon coatings. The conclusions are as follows:

- Photonic curing was able to convert a polymer resin precursor into a bulk glassy carbon structure which was $s p^{2}$ dominant, as indicated by Raman spectroscopy, and closely resembled a conventional derived glassy carbon structure produced from thermal treatment at $800{ }^{\circ} \mathrm{C}$.

- Photonic curing was able to convert the precursor in around $1 \mathrm{~min}$, a manifold reduction in processing time compared to the approximately $20 \mathrm{~h}$ processing time when using a conventional thermal conversion method.

- Carbon coatings produced photonically were resistant to bending, highly smooth and did not show any evidence of surface defects, such as pinholes, delamination or scratches.

- XPS analysis suggested a difference in the immediate surface chemistry of the photonic cured samples compared to thermally derived. This is likely associated with the different environmental conditions around the sample during treatment.

- The ability to rapidly photonically manufacture glassy carbon coatings expands the potential window of applications of glassy carbons for high volume applications such as coatings for energy storage, rapid manufacture of complex electrically conductive shapes, and the opportunity to use temperature sensitive substrates.

\section{Acknowledgements}

This research was financially supported by the EPSRC (Engineering and Physical Sciences Research Council) (EP/N509553/1, EP/N013727/1). Raman spectroscopy, XPS and SEM were performed using the Advance Imaging of Materials (AIM) facilities at Swansea University, supported by the European Regional Development Fund through the Welsh Government (80708) \& EPSRC (EP/M028267/1). James McGettrick thanks EPSRC vis SPECIFIC (EP/ N020863/1).

\section{Author contributions}

BdeB Conceptualisation, Methodology, Investigation, Formal analysis, Writing-original draft, Visualisation; CP Methodology, Writing-Review and Editing, Supervision; YCL Methodology, Investigation; AA Conceptualisation; JM Formal analysis, Investigation; DD Conceptualisation, Methodology, Resources, Writing-review \& editing, Supervision, Funding acquisition, Project administration.

\section{Declarations}

'Yin Cheung Lau'.Conflict of interest The authors declare that they have no known competing financial interests or personal relationships that could have appeared to influence the work reported in this paper.

Open Access This article is licensed under a Creative Commons Attribution 4.0 International License, which permits use, sharing, adaptation, distribution and reproduction in any medium or format, as long as you give appropriate credit to the original author(s) and the source, provide a link to the Creative Commons licence, and indicate if changes were made. The images or other third party material in this article are included in the article's Creative Commons licence, unless indicated otherwise in a credit line to the material. If material is not included in the article's Creative Commons licence and your intended use is not permitted by statutory regulation or exceeds the permitted use, you will need to obtain permission directly from the copyright holder. To view a copy of this licence, visit http://creativecommons.org/licen ses/by/4.0/. 


\section{References}

[1] Harris PJF (1997) Structure of non-graphitising carbons. Int Mater Rev 42(5):206-218. https://doi.org/10.1179/imr.1997. 42.5.206

[2] Thrower PA (1999) Glassy carbon. In: Zuckerman JJ, Atwood JD (eds) Inorganic reactions and methods: formation of ceramics, vol 18. Wiley-VCH, Inc, pp 163-164. h ttps://doi.org/10.1002/9780470145333.ch113

[3] Harris PJF (2004) Fullerene-related structure of commercial glassy carbons. Philos Mag 84:3159-3167. https://doi.org/ $10.1080 / 14786430410001720363$

[4] Zittel HE, Miller FJ (1965) A glassy-carbon electrode for voltammetry. Anal Chem 37:200-203. https://doi.org/10.10 21/ac60221a006

[5] Van der Linden WE, Dieker JW (1980) Glassy carbon as electrode material in electro- analytical chemistry. Anal Chim Acta 119:1-24. https://doi.org/10.1016/S0003-2670(00)00025-8

[6] Yagi S, Tanaka A, Ichikawa Y, Ichitsubo T, Matsubara E (2013) Electrochemical stability of magnesium battery current collectors in a grignard reagent-based electrolyte. J Electrochem Soc 160:C83-C88. https://doi.org/10.1149/2. 033303jes

[7] Bokros JC, Bokros JC (1971) The fourth Charles E. Pettinos Award was presented at the twelfth biennial conference on carbon in Pittsburgh, Pennsylvania to J. C. Bokros in recognition of his, Carbon N. Y. I

[8] Markle DH, Grenoble DE, Melrose RJ (1975) Histologic evaluation of implants in dogs. Biomat Med Dev Art Org 3:97-114

[9] Wang J, Li M, Shi Z, Li N, Gu Z (2002) Direct electrochemistry of cytochrome $\mathrm{c}$ at a glassy carbon electrode modified with single-wall carbon nanotubes. Anal Chem 74:1993-1997. https://doi.org/10.1021/ac010978u

[10] Fagan DT, Hu IF, Kuwana T (1985) Vacuum heat treatment for activation of glassy carbon electrodes. Anal Chem 57:2759-2763. https://doi.org/10.1021/ac00291a006

[11] McDermott MT, McCreery CA, McDermott RL (1993) Scanning tunneling microscopy of carbon surfaces: relationships between electrode kinetics, capacitance, and morphology for glassy carbon electrodes. Anal Chem 65:937-944. https://doi.org/10.1021/ac00055a017

[12] Zhang L, Yuan R, Chai Y, Li X (2007) Investigation of the electrochemical and electrocatalytic behavior of positively charged gold nanoparticle and 1-cysteine film on an $\mathrm{Au}$ electrode. Anal Chim Acta 596:99-105. https://doi.org/10. 1016/j.aca.2007.05.050

[13] Plock CE, Vasquez J (1969) Use of glassy carbon as a working electrode in controlled potential coulometry. Talanta 16:1490-1492. https://doi.org/10.1016/0039-9140(69)80204-3
[14] Gattrell M, Kirk DW (1990) The electrochemical oxidation of aqueous phenol at a glassy carbon electrode. Can J Chem Eng 68:997-1003. https://doi.org/10.1002/cjce.5450680615

[15] Swain GM (1994) The susceptibility to surface corrosion in acidic fluoride media: a comparison of diamond, HOPG, and glassy carbon electrodes. J Electrochem Soc 141:3382-3393. https://doi.org/10.1149/1.2059343

[16] Wall C, Zhao-Karger Z, Fichtner M (2014) Corrosion resistance of current collector materials in bisamide based electrolyte for magnesium batteries. ECS Electrochem Lett 4:C8-C10. https://doi.org/10.1149/2.0111501eel

[17] Yi Y, Weinberg G, Prenzel M, Greiner M, Heumann S, Becker S, Schlögl R (2017) Electrochemical corrosion of a glassy carbon electrode. Catal Today 295:32-40. https://doi. org/10.1016/j.cattod.2017.07.013

[18] Lewis IC, Pirro TA, Miller DJ (1995) Method for making a graphite component covered with a layer of glassy carbon. US Patent 5,476,679

[19] Tarvainen T, Paronen I, Tunturi T et al (1998) Bone remodelling in the pores and around load bearing transchondral isoelastic porous-coated glassy carbon implants: experimental study in rabbits. J Mater Sci Mater Med 9:509-515. https://doi.org/10.1023/A:1008835821107

[20] Jenkins GM, Grigson CJ (1979) The fabrication of artifacts out of glassy carbon and carbon-fiber-reinforced carbon for biomedical applications. J Biomed Mater Res 13:371-394. h ttps://doi.org/10.1002/jbm.820130304

[21] Johnson KK, Jones LE (1997) Phenol-formaldeyde resin structure for the synthesis of glassy carbon. NYS School of Ceramic Engineering and Material Science at Alfred University Alfred, New York, pp 478-479

[22] Katović Z (1967) Curing of resole-type phenol-formaldehyde resin. J Appl Polym Sci 11:85-93. https://doi.org/10. 1002/app.1967.070110106

[23] Bhatia G, Aggarwal RK, Malik M, Bahl OP (1984) Conversion of phenol formaldehyde resin to glass-like carbon. J Mater Sci 19:1022-1028. https://doi.org/10.1007/BF00540472

[24] Laušević Z, Marinković S (1986) Mechanical properties and chemistry of carbonization of Phenol formaldehyde resin. Carbon N Y 24:575-580. https://doi.org/10.1016/0008-622 3(86)90148-X

[25] Schueller OJA, Brittain ST, Whitesides GM (1997) Fabrication of glassy carbon microstructures by pyrolysis of microfabricated polymeric precursors. Adv Mater 9:477-480. https://doi.org/10.1002/adma.19970090604

[26] Schneller OJA, Brittain ST, Whitesides GM (1999) Fabrication of glassy carbon microstructures by soft lithography. Sens Actuators A Phys 72:125-139. https://doi.org/10.1016/ s0924-4247(98)00218-0 
[27] Fitzer E, Schäfer W (1970) The effect of crosslinking on the formation of glasslike carbons from thermosetting resins. Carbon N Y 8:353-364. https://doi.org/10.1016/0008-6223 (70)90075-8

[28] Šupová M, Svítilová J, Chlup Z, Černý M, Weishauptová Z, Suchý T, MacHovič V, Sucharda Z, Žaloudková M (2012) Relation between mechanical properties and pyrolysis temperature of phenol formaldehyde resin for gas separation membranes. Ceram-Silikaty 56:40-49

[29] Fitzer E, Schaefer W, Yamada S (1969) The formation of glasslike carbon by pyrolysis of polyfurfuryl alcohol and phenolic resin. Carbon N Y 7:643-648. https://doi.org/10. 1016/0008-6223(69)90518-1

[30] Guillot MJ, Schroder KA, Mccool SC (2016) IMECE201287674 1-9

[31] Cui HW, Jiu JT, Nagao S, Sugahara T, Suganuma K, Uchida $\mathrm{H}$, Schroder KA (2014) Ultra-fast photonic curing of electrically conductive adhesives fabricated from vinyl ester resin and silver micro-flakes for printed electronics. RSC Adv 4:15914-15922. https://doi.org/10.1039/c4ra00292j

[32] Das S, Yang B, Gu G, Joshi PC, Ivanov IN, Rouleau CM, Aytug T, Geohegan DB, Xiao K (2015) High-performance flexible perovskite solar cells by using a combination of ultrasonic spray-coating and low thermal budget photonic curing. ACS Photon 2:680-686. https://doi.org/10.1021/ac sphotonics.5b00119

[33] Schroder KA (2011) Mechanisms of photonic curing ${ }^{\mathrm{TM}}$ : processing high temperature films on low temperature substrates, Tech. Proc. 2011 NSTI Nanotechnol. Conf. Expo, NSTI-Nanotech 2011. 2:220-223

[34] Akhavan V, Schroder K, Pope D, Farnsworth S (2013) Processing thick-film screen printed Metalon ${ }^{\circledR} \mathrm{CuO}$ reduction ink with PulseForge ${ }^{\circledR}$ tools. Coat Int 46:14-17

[35] Assaifan AK, Alshehri NA, Lewis AR, Samavat S, Lau YC, Deganello D, Teng KS (2020) Effect of intense pulsed light on hydrothermally grown $\mathrm{ZnO}$ nanowires. Mater Lett 271:127797. https://doi.org/10.1016/j.matlet.2020.127797

[36] Cronin HM, Stoeva Z, Brown M, Shkunov M, Silva SRP (2018) Photonic curing of low-cost aqueous silver flake inks for printed conductors with increased yield. ACS Appl Mater Interfaces 10:21398-21410. https://doi.org/10.1021/acsami. $8 b 04157$

[37] Bouchet-Fabre B, Marino E, Lazar G, Zellama K, Clin M, Ballutaud D, Abel F, Godet C (2005) Spectroscopic study using FTIR, Raman, XPS and NEXAFS of carbon nitride thin films deposited by RF magnetron sputtering. Thin Solid Films 482:167-171. https://doi.org/10.1016/j.tsf.2004.11.166

[38] Baldan MR, Almeida EC, Azevedo AF, Gonçalves ES, Rezende MC, Ferreira NG (2007) Raman validity for crystallite size $\mathrm{L}$ a determination on reticulated vitreous carbon with different graphitization index. Appl Surf Sci 254:600-603. https://doi.org/10.1016/j.apsusc.2007.06.038

[39] Jurkiewicz K, Pawlyta M, Zygadło D, Chrobak D, Duber S, Wrzalik R, Ratuszna A, Burian A (2018) Evolution of glassy carbon under heat treatment: correlation structure-mechanical properties. J Mater Sci 53:3509-3523. https://doi.org/10. 1007/s10853-017-1753-7

[40] Kaciulis S (2012) Spectroscopy of carbon: from diamond to nitride films. Surf Interface Anal 44:1155-1161. https://doi. org/10.1002/sia.4892

[41] Baranov AV, Bekhterev AN, Bobovich YS, Petrov VI (1987) Interpretation of some singularities in Raman-spectra of graphite and glass carbon. Opt I Spektrosk 62:1036-1042

[42] Nakamizo M, Kammereck R, Walker PL (1974) Laser Raman studies on carbons. Carbon N Y 12:259-267. http s://doi.org/10.1016/0008-6223(74)90068-2

[43] Vidano R, Fischbach DB (1978) New lines in the Raman spectra of carbons and graphite. J Am Ceram Soc 61:13-17. https://doi.org/10.1111/j.1151-2916.1978.tb09219.x

[44] Vidano RP, Fischbach DB, Willis LJ, Loehr TM (1981) Observation of Raman band shifting with excitation wavelength for carbons and graphites. Solid State Commun 39:341-344. https://doi.org/10.1016/0038-1098(81)90686-4

[45] Ferrari AC, Robertson J (2004) Raman spectroscopy of amorphous, nanostructured, diamond-like carbon, and nanodiamond. Philos Trans R Soc A Math Phys Eng Sci 362:2477-2512. https://doi.org/10.1098/rsta.2004.1452

[46] Ferrari AC, Robertson J (2000) Interpretation of Raman spectra of disordered and amorphous carbon. Phys Rev B 61:14095-14107. https://doi.org/10.1103/PhysRevB.61. 14095

[47] Lim Y, Chu JH, Lee DH, Kwon SY, Shin H (2017) Increase in graphitization and electrical conductivity of glassy carbon nanowires by rapid thermal annealing. J Alloys Compd 702:465-471. https://doi.org/10.1016/j.jallcom.2017.01.098

[48] Mezzi A, Kaciulis S (2010) Surface investigation of carbon films: From diamond to graphite. Surf Interface Anal 42:1082-1084. https://doi.org/10.1002/sia.3348

[49] Briggs D (2005) X-ray photoelectron spectroscopy (XPS), Handb. Adhes. Second Ed. 621-622. https://doi.org/10.100 2/0470014229.ch22

[50] McGuire GE (1979) Carbon. In: Auger electron spectroscopy reference manual. Springer, Boston, MA. https://d oi.org/10.1007/978-1-4757-1702-0_2

Publisher's Note Springer Nature remains neutral with regard to jurisdictional claims in published maps and institutional affiliations. 